\title{
Sex therapy: brief historic and current perspectives
}

\begin{abstract}
Now more than five decades old, the field of sex therapy remains active, continuously incorporating in its practice advances in psychology and medicine. In this article, we present a brief historical perspective of the sex therapy practice as well as its present state. We discuss the how the current biopsychosocial paradigm advocates sexual dysfunction as an interaction of predisposing, precipitating, and maintaining factors and calls for the cooperation of professionals from different areas to effectively evaluate and treat patients. We conclude that the concerns of modern sex therapy have moved past rescuing sexual function and toward minimizing distress while enhancing sexual satisfaction.
\end{abstract}

Keywords: sexuality, sexual dysfunction, psychotherapy, sexology
Volume 5 Issue 5 - 2017

\author{
Barbara Braga de Lucena, Carmita Helena \\ Najjar Abdo \\ Departament of Psychiatry, University of Sao Paulo, Brazil
}

Correspondence: Barbara Braga de Lucena, Program of Studies in Sexuality (ProSex), Department and Institute of Psychiatry, University of São Paulo, R. Dr. OvÃdio Pires de Campos, 785-Cerqueira CÃ@sar, SÃ£o Paulo-01060-970, Brazil, Tel (2I5)3989762/55(I I)9837524II

Email barbarabdelucena@gmail.com

Received: June 10, 2017 | Published: July 21, 2017

\section{Introduction}

In the last 50years, the interest in sexual medicine and sex therapy has grown enormously. Ever since sexual problems stopped being attributed exclusively to unconscious conflicts, sexology has changed in theoretical, methodological, and diagnostic aspects. ${ }^{1}$ Contributions from the various medical specialties, modern psychology, and social constructionism have allowed a broader understanding of the sexual difficulties. Despite the recognized importance of sexual aspects in the quality of life. ${ }^{2}$ the prevalence of sexually unsatisfied individuals remains high, even according to the most conservative prevalence studies. ${ }^{3}$ Being capable of identifying, and treating or appropriately refer patients with sexual dysfunction is paramount in the contemporary clinical activity.

\section{Discussion}

Until the 1950s, classical psychoanalytic concepts guided the understanding and treatment of sexual problems. The symptoms in adult life were understood as unresolved conflicts during the early stages of childhood. ${ }^{3}$ In late 1950s, when the behaviorist perspective gained force, Masters and Johnson began their studies based on direct observations of the human sexual response. Based on these experiments, they divided the sexual response into phases (excitation, plateau, orgasm, and resolution), each presenting specific physiological processes. For them, sexual dysfunction was most often response to performance anxiety. Thus, treatment should be guided toward anxiety reduction in order to restore a healthy sexual function. ${ }^{4}$ In 1958, Masters and Johnson used the term sexual therapy for the first time in a research proposal submitted to the chancellor of the University of Washington. Although this document has been lost, the authors mention in a later publication plans for a research program in psychotherapy targeted to sexual dysfunction. ${ }^{5}$ According to some authors, ${ }^{6}$ the birth of sexual therapy occurs with the publication of the book Human Sexual Inadequacy (Masters and Johnson, 1970). ${ }^{7}$

In 1974, the psychiatrist Helen Singer Kaplan publishes the book "The New Sex Therapy", ${ }^{8}$ in which integrates the psychoanalytic model to the sexual therapy proposed by Masters and Johnson. For her, the treatment of sexual dysfunction should be planned according to its etiology, proposing the distinction between recent and remote etiologic causes. For recent causes, behavioral exercises; to remote ones, traditional psychodynamic methods. Since then, the etiology of sexual dysfunctions has been considered in binary terms: remote or recent; psychological or organic. Although this division is useful for clinical practice, these categories are neither exclusive categories nor can be taken considered separately.

\section{Diagnoses and therapeutic planning}

The current biopsychosocial paradigm advocates that the sexual dysfunction has predisposing factors (prior to the complaint), precipitating factors (triggers for their onset) and maintaining factors (those that contribute to the problem persistence). ${ }^{3}$ It is important to highlight that often the factors that lead to the emergence of a sexual dysfunction are not the same that sustain it.

Thus, the assessment of sexual dysfunction should include:

i. Assessment of sexual function, including feelings, thoughts, and receptivity presented during sexual activity;

ii. Elucidation of possible comorbidities;

iii. Identification of etiological hypotheses and maintaining factors;

iv. Identification of the treatment objectives and a therapeutic planning; and

v. Clear and constructive feedback to the patient about the work to be accomplished. ${ }^{9,10}$

Physical and hormonal assessments are mandatory to better understand the sexual dysfunction and elaborate adequate therapeutic plans. ${ }^{10}$ Ideally, professionals with different backgrounds (e.g: gynecologist, urologist, psychiatrist, psychologist, physiotherapist) work together for the patient's well-being.

The therapeutic plan is the main guide principle of the work ahead. It should specify the diagnostic formulation, the objectives to be achieved and the therapeutic conduct with details of the procedures and interventions to be carried out, although it can revised to match the demands that emerge during the visits. It is personalized, not only with respect to the sexual dysfunction presented, but also the individual in totality. For instance, masturbatory training is proven 
effective for female orgasm disorder. ${ }^{11,12}$ However, it would not be included, in principle, in the therapeutic planning of a woman who has restrictions towards the masturbatory practice (either moral, religious or educational).

\section{Sex therapy nowadays}

Currently, the term sexual therapy refers to the whole of interventions, based on different theoretical perspectives aimed at the treatment of sexual difficulties. It generally follows the principles of brief psychotherapy, in which therapist and patient are focused on specific issues related to sexual performance. Also, it may occur in individual, couple or group therapy formats. Despite the fact that there is no single theory underlying sex therapy and that professionals with diverse psycho-backgrounds can be sex therapists, some elements are common to psychotherapies focus on sexual dysfunctions: ${ }^{6,13}$

i. They speak openly about sex;

ii. They include psychoeducation, counseling, sexual permission, training on communication, exercises for body exploration and awareness;

iii. They do not preclude medical interventions. Instead, they are often combined;

iv. They rarely address a single main sexual complaint, but rather the sexual experience as a whole;

v. They involve customized strategies that go from psychoeducation and basic counseling to more specialized intervention, using contributions from different psychotherapeutic schools.

There is evidence that people with sexual dysfunction tend to respond to sexual situations with high levels of anxiety, negative effect, and failure expectation, ${ }^{14}$ highlighting the influence of cognitive distraction (attentional focus on non-excitatory stimulus) during the sexual activity. ${ }^{15,16}$ Therefore, investigating the content of the thoughts that distract these individuals plays an important role in their rehabilitation. ${ }^{17}$ Identifying automatic thoughts, cognitive reconstruction and attentional training during sexual activity have been shown to be effective in the treatment of all sexual dysfunctions. ${ }^{18}$

\section{Sex therapy based on evidence}

The practice of evidence-based psychotherapy is the best available research evidence with the clinical practice in the context of preferences and characteristics of the patient. ${ }^{19}$ In sex therapy, it of the number of clinical trials testing interventions remains insufficient. ${ }^{18}$ Nevertheless, there are promising results. In Melnik and $\mathrm{Abdo}^{20}$ patients were randomized into three groups: patients who performed group sex therapy and received 50mg of sildenafil, patients who only received 50mg of sildenafil, and patients who only performed group sex therapy.

The interventions lasted for six months and all groups presented improvement. However, the groups that received psychotherapy had post-treatment scores higher than those in the group that only received the medication. Subsequently, Abdo et al.,21 confirmed that the combination treatment (sildenafil and sexual therapy) is more effective than the separate interventions. McCabe et al., ${ }^{22}$ investigated the effectiveness of 10 weeks of cognitive-behavioral therapy for people with erectile dysfunction compared with being in a waiting list. They found a significant improvement in the group that participated in the intervention. In the study by van Lankveld et al., ${ }^{23}$ men with erectile dysfunction, premature ejaculation, and low sexual desire, as well as their partners, were randomized between cognitive behavioral intervention that included bibliotherapy, psychoeducation and sensorial focus exercises and a wait list. After the 10weeks of treatment men in the therapy group reported more, and, at the end, the treated men reported improvement of their sexual function $(41.4 \%$ versus $12.5 \%)$. For premature ejaculation, Oguzhanoglu et al., ${ }^{24}$ showed that sex therapy is as effective as $20 \mathrm{mg}$ of fluoxetine, the first line drug for the treatment of this dysfunction. For women, the efficacy of cognitive-behavioral therapy has been reported in the treatment of all sexual dysfunctions. ${ }^{18}$ The most recent finding is the effectiveness of mindfulness technique-type of meditative practice which aims at acceptance and awareness of the present moment without judgment-in the treatment of lack of sexual interest or sexual pain during penetration. ${ }^{25}$ Neuroimaging studies show that patients submitted to this technique have a brain activity reduction in areas associated to pain. ${ }^{26,27}$

\section{Conclusion}

The evolution of sex therapy follows the progress of sexology research. Good examples of research innovations that were incorporated in the clinical practice include: the use of phosphodiesterase-5 inhibitors (PDE-5) for the treatment of erectile dysfunction and the selective serotonin reuptake inhibitors (SSRIs) for the treatment of premature ejaculation, the distinction between the male and female sexual responses, and the biopsychosocial aspects of sexual dysfunction. However, the goals of sex therapy typically are different from those of the clinical trials. The success sex therapy cannot be measured by sexual frequency or increases in the time before ejaculation. More than performance, the concern is the subjective expression of sexuality. More than rescuing sexual function, the concern is the distress minimization while enhancing the patient's sexual satisfaction.

\section{Acknowledgements}

None.

\section{Conflict of interest}

The author declares no conflict of interest.

\section{References}

1. Leiblum S. Principles and Practice of Sex Therapy. 4th ed. USA: Guilford Press; 2006. p. 1-556.

2. OMS. Classificação de Transtornos Mentais e de Comportamento da CID10. Descrições Clínicas e Diretrizes Diagnósticas, Portugal; 1993.

3. Althof S. Sex therapy: advances in paradigms, nomenclature, and treatment. Acad Psychiatry. 2010;34(5):390-396.

4. Lo Piccolo J, Lo Piccolo L. Handbook of sex therapy. In: Leslie editor. USA: Plenum Press; 1978.

5. Masters WH, Johnson VE. Principles of the new sex therapy. Am $J$ Psychiatry. 1976;133(5):548-554.

6. Binik YM, Meana M. The future of sex therapy: specialization or marginalization? Arch Sex Behav. 2009;38(6):1016-1027.

7. Masters WH, Johnson VE. Human sexual inadequacy. Little, UK: Brown and Company; 1970.

8. Kaplan HS. The New Sex Therapy: Active Treatment of Sexual Dysfunctions. 
USA: Psychology Press; 1974. p. 1-544.

9. Lewis RW, Fugl Meyer KS, Corona G, et al. Definitions/ epidemiology/ risk factors for sexual dysfunction. $J$ Sex Med. 2010;7(4 Pt 2):1598-1607.

10. Leiblum SR, Wiegel M. Psychotherapeutic interventions for treating female sexual dysfunction. World J Urol. 2002;20(2):127-136.

11. Salmani Z, Zargham-Boroujeni A, Salehi M, et al. The existing therapeutic interventions for orgasmic disorders: recommendations for culturally competent services, narrative review. Iran J Reprod Med. 2015;13(7):403412

12. de Lucena BB, Abdo $\mathrm{CH}$. Personal factors that contribute to or impair women's ability to achieve orgasm. Int J Impot Res. 2014;26(5):177-181.

13. Fleury HJ, Abdo CHN. Tratamento psicoterápico para disfunção sexual feminina/Psychotherapeutic treatment for female sexual dysfunction. Diagn Tratamento. 2012;17(3):133-137.

14. Barlow DH. Causes of sexual dysfunction: the role of anxiety and cognitive interference. J Consult Clin Psychol. 1986;54(2):140-148.

15. Elliott AN, O'Donohue WT. The effects of anxiety and distraction on sexual arousal in a nonclinical sample of heterosexual women. Arch Sex Behav. 1997;26(6):607-624.

16. Dove NL, Wiederman MW. Cognitive distraction and women's sexual functioning. J Sex Marital Ther. 2000;26(1):67-78.

17. Nobre PJ, Pinto-Gouveia J. Cognitive schemas associated with negative sexual events: a comparison of men and women with and without sexual dysfunction. Arch Sex Behav. 2009;38(5):842-851.

18. Berner M, Günzler C. Efficacy of psychosocial interventions in men and women with sexual dysfunctions--a systematic review of controlled clinical trials: part 1-the efficacy of psychosocial interventions for male sexual dysfunction. J Sex Med. 2012;9(12):3089-3107.
19. Norcross JC, Beutler LE, Levant RF. Evidence-based practices in mental health: debate and dialogue on the fundamental questions. USA: American Psychological Association; 2005. p. 1-435.

20. Melnik T, Abdo CH. Psychogenic erectile dysfunction: comparative study of three therapeutic approaches. J Sex Marital Ther. 2005;31(3):243-255.

21. Abdo $\mathrm{CH}$, Afif-Abdo J, Otani F, et al. Sexual satisfaction among patients with erectile dysfunction treated with counseling, sildenafil, or both. $J$ Sex Med. 2008;5(7):1720-1726.

22. McCabe MP, Price E, Piterman L, et al. Evaluation of an internet-based psychological intervention for the treatment of erectile dysfunction. Int J Impot Res. 2008;20(3):324-330.

23. Van Lankveld JJDM, Everaerd W, Grotjohann Y. Cognitive-behaviora bibliotherapy for sexual dysfunctions in heterosexual couples: A randomized waiting-list controlled clinical trial in the Netherlands. The Journal of Sex Research. 2001;38(1):51-67.

24. Oguzhanoglu NK, Ozdel O, Aybek Z. The efficacy of fluoxetine and a stopstart technique in the treatment of premature ejaculation and anxiety. J Clin Psychopharmacol. 2005;25(2):192-194.

25. Brotto LA, Chivers ML, Millman RD, et al. Mindfulness-based sex therapy improves genital-subjective arousal concordance in women with sexual desire/arousal difficulties. Arch Sex Behav. 2016;45(8):1907-1921.

26. Dunkley CR, Brotto LA. Psychological treatments for provoked vestibulodynia: integration of mindfulness-based and cognitive behavioral therapies. J Clin Psychol. 2016;72(7):637-650.

27. Brotto LA, Goldmeier D. Mindfulness interventions for treating sexual dysfunctions: the gentle science of finding focus in a multitask world. $J$ Sex Med. 2015;12(8):1687-1689. 